\title{
Observing the author-editor relationship: Recordkeeping and literary scholarship in dialogue
}

\author{
In the call for papers for this special issue, a lack of dialogue was noted between 'archivists and \\ literary scholars'. This article has arisen from a collaboration across that divide, between two \\ individuals who between them embody multiple identities of archivist and publisher, archival and \\ literary scholar. The purpose of this collaboration was to establish a common frame of reference \\ which would encompass and give equal weight to the concerns and working contexts of both. To \\ assist in this aim, both researchers agreed that neither field of archives or literary scholarship \\ would be privileged. The focus in this study is on the relationship between the author and the \\ editor within the academic publishing sector. With these parameters set as the starting point, \\ research questions were drawn up from both perspectives to guide the project. These questions \\ were, to some extent, addressed, but a more important outcome of the process was the \\ development of a common frame of reference in which to continue the dialogue, through a \\ broader and more abstract idea of the scholarly record and not just one of records as material \\ resources for literary scholarship.
}

Keywords: publishing; archives; scholarship; records; editors; literary

\section{Introduction}

In the call for papers for this special issue, the context was set as 'born-digital records in literary and publishers' archives', highlighting the shift towards the use of digital technologies. The disruptive effect of such technologies is widely recognised in all fields and aspects of society and in this respect it can be seen as a common problem facing us all. What concerned the researchers at the outset of this project however, was the specific way in which this problem was being held in common between their individual areas of concern. For the call makes clear that digital disruption was being considered in terms of its 'impact on issues of access'. It was felt that this brought the risk of the two fields being brought, not into dialogue, but into a well-worn relationship pattern whereby archivists serviced the needs of literary scholars by providing access to materials labelled 'records', which literary scholars then used, not understanding the processes that had gone into creating them. There is not anything wrong with this form of relationship per se, but the researchers recognised the need to push beyond that to explore how both fields can work to support each other more effectively in the future. Terry Cook, for 
example, has suggested that our attempts to deal with born-digital records are limited when we do not seek to transcend our existing conceptualisations and past patterns of behaviour. ${ }^{1}$

With this in mind, a project was designed to work on two levels simultaneously. On the first of these levels, and in order to structure a time-limited project, a focus for the research was selected in the form of the relationship between the author and the editor in the academic publishing sector. This focus was chosen because, whilst it did not automatically imply the sort of relationship between archivists and literary scholars identified above, it still allowed both researchers to address questions of relevance to their own fields individually. These questions and their relevance will be outlined in the following sections. Through the research, these questions were addressed, but ultimately answering them was not the end goal: the idea was rather to work on a second level, using this process as a means of developing an alternative frame of reference, and an alternative way of defining the relationship and overlap between the two fields. In this way, the research chose to prioritise process over outcomes in order to address the relationship between two different perspectives and research fields. As such, it can be seen as influenced by and in some ways analogous to ideas expressed by Johnston and Marwood in developing a framework for action heritage. ${ }^{2}$

The rest of the article must be read with this in mind and is structured in the following way. Firstly, in the next two sections the topic chosen - 'the relationship between the author and the editor' - is considered from both a literary scholarship and an archival frame. In these sections, it becomes clear that each field or frame does have its own scholarship and concerns, but equally that these do overlap and can be brought together in a way that is not just about providing access to records, but also about questions of evidence. In the next two sections findings are presented in a way designed to speak more to concerns identified as specific to one or other of the two fields. As such, one focuses on changing recordkeeping practices and on addressing the question of a tension between personal and corporate archives, and the other speaks to the question of the changing nature of the working relationship between the author and the editor and the complexities of capturing those workings for investigation by future literary scholars.

Finally, the article shifts to its second level, with a section that explores the overlap that emerged through the project; a common frame of reference and a common concern with the health and sustainability of the scholarly record are developed for literary scholarship and 
archivists alike. In so doing, the danger of not acknowledging differences of perspective is highlighted, stressing that in their common concern with the health of the scholarly record, both archivists and literary scholars place themselves within a common system where records are no longer just things passed between them and they must work together for a common cause.

\section{Introducing a Literary Scholarship Frame}

The relationship between an author and an editor is a complex one, particularly in terms of how it impacts on the final, published version of any work. Within academic publishing contexts in particular, where canonical works are mediated by textual scholars as well as academic publishing editors, the correspondences between these two agents can reveal valuable evidence regarding the establishment of textual authority. Literary scholarship has increasingly drawn upon book history methodologies to explore these interconnected communications, for, as Helen Gardner emphasised:

In no other subject is the pupil brought more immediately and continuously into contact with original sources, the actual material of his study. In no other subject is he so able and so bound to make his own selection of the material he wishes to discuss, or able so confidently to check the statements of authorities against the documents on which they are based. ${ }^{3}$

Although Gardner was not referring specifically to publishing archives, but rather to the wider body of materials connected to any text which make literary research such a rich field, this article focuses on the publisher's significant place in that arena, specifically the archives which reflect publishing practice. Publishers' archives hold materials of great value to scholars investigating the histories of texts, of authors, and of the historical, social, political and cultural contexts in which they were created. And yet, as Iain Stevenson remarked, despite publishing histories being 'enormously powerful, flexible, useful and important' they 'remain curiously under-regarded, poorly documented, and misunderstood.'4 
The author-editor relationship within an academic press balances scholarly expertise against pragmatic production needs, drawing upon a range of peripheral agents for support and validation before the final text can be published. The working relationship created between the editor and the author can and often does outlast the formal time frame of a book's publication schedule, and that partnership, often created over long periods of time, can form a significant part of a scholar's academic identity. This link with identity, unique to the arts, humanities, and social sciences, has been discussed by Geoffrey Crossick in his report to the Higher Education Funding Council for England in 2015: he said that "the term "thinking through the book" emerged through the consultations, and it is a powerful concept, effectively reintegrating the research into the writing process itself . . in a very real sense, the book is part of the author's identity. $^{5}$

By the time the reports from the UK's Arts and Humanities Research Council/British Library Academic Book of the Future Project were released, two years later, Michael Jubb concluded that there was a shift away from the engagement of scholars with publishing editors, saying that 'survey evidence suggests that many researchers value such support [. . . but some see it as an incursion on their own role.' Furthermore, 'among academic publishers with longer lists - and lower sales per title - such hands-on engagement between editors and authors is less common than it was two decades ago., 6

Such concerns within the literary scholarship frame lead to a series of questions about the materials now being produced which evidence the author-editor relationship, and that will help make it accessible for productive investigation by literary scholars in the future. There are also questions this raises about the changing nature of the author-editor relationship and the 
possibility that the sort of relationship literary scholarship has assumed and explored in the past might not even exist to be evidenced any more.

\section{Introducing a Recordkeeping Frame}

Once the concerns of literary scholarship (in respect of the author-editor relationship) start to focus, at least in part, on questions of evidence and evidencing, overlap can be found with the concerns of recordkeeping and questions can be framed such as:

- what evidences and records the author-editor relationship and what form does such evidence and record take?

- how do these forms flow around the organisation?

- how has the change to digital mechanisms of communication and information affected the above?

In order to address such questions, as well as that of the changing nature of the author-editor relationship itself, two interviews were carried out with editors at a major academic publisher. One of the researchers knew both of these editors, as she had worked with them on a number of publishing projects. The interviewees were also known to each other as one (Bethany Thomas) had recently taken over some of the duties of the other (Linda Bree), following her retirement as Editorial Director for the Arts and Humanities.

This fact was another reason why these particular editors were chosen, as it allowed for a good view of change over time, with the editors between them able to comment on both past and current/changing practices. Another reason why sight of this transition was felt to be important was its potential for interrogating the difference between personal and organisational relationships and the role of records in mediating the two. For authors with a long-standing working relationship with a particular editor, adjusting to the changes in practice when that 
editor moves on, and another person fills that role, can be challenging. Similarly, the new editor in post was in the situation of having to 'take over' a large number of both organisational and personal relationships and questions could be asked about the extent to which the existing records had supported her in that task.

In this way, it was hoped that attention could also be given to another concern, this time one found specifically within the archival community, namely a fault-line long apparent in its discourse and labelled, by scholars McKemmish and Piggott, 'the binary opposition of the personal and corporate archive'. ${ }^{7}$ This fault-line has been probed by a number of scholars over the years, and cases have been made for both clear differences splitting and essential similarities uniting either side of it. ${ }^{8}$ Whenever the debate is raised however, it is often accompanied by calls to reconsider archival thinking and it seems to hold at its heart a drive to widen archival scholarship's conceptualisation of the record; this conceptualisation viewed as having been too heavily modelled in the past on governmental or organisational contexts. It was hoped that in approaching this issue in parallel with another one from literary scholarship, it would be possible to avoid getting drawn back too much into these more exclusive, theoretical, purely recordkeeping concerns and to offer a slightly different perspective and framing of the problem, if problem it was.

This additional focus was also the reason why it was not felt necessary to interview any authors. Authors did not embody the sort of multiple (corporate/personal) relationship in recordkeeping discussed above in the same way that the editors did. Nonetheless, the author perspective was not completely absent, as the researcher who held that relationship with the interviewees was able to bring it into the conversations, and did so at a number of points. Both 
researchers were present at both interviews, but the questioning was led by the researcher who did not also hold a prior personal relationship with either of the editors.

Alongside the interviews, further contextual information was gathered about recordkeeping processes in the organisation from its archivist and the researchers also looked together at the materials arising from the author-editor relationship which had already made it into the corporate archive. When analysing this data, alongside the transcribed interviews, the researchers first considered the findings, within the recordkeeping and literary scholarship frames separately, before developing a more common frame of reference in which the two frames started to combine.

\section{Findings from a recordkeeping frame}

It was clear from the interviews with both editors that recordkeeping practices had changed over time and this change was most generally expressed in the following terms: 'there was a general culture of paper filing and I think over the last, pretty recently really, that culture of paper filing has disappeared almost entirely' (Linda). Digging beneath the surface however, a more nuanced picture was revealed, for, although the new editor in post did feel that her predecessor had printed out too much, she also reported that she was starting to adopt some of her paper practices:

She had paper files for her pending ${ }^{9}$ projects as well [...] she would print out all the relevant correspondence and the proposal and everything, and literally wrap a piece of paper around it, and write the author and then relevant information on the front, paper clip it and put it in a folder, and I've started doing that now (Bethany).

Paper filing then had not yet disappeared and there did still seem to be both a practice of creating paper files and a wider mechanism or workflow associated with them: 
So, the pending stuff sits in my work space, the contracted stuff sits in my editorial assistant's workspace $[\ldots]$ once a project has been published I'm not sure how long but I think a few months after that, $[\ldots][$ he] actually has time to go through and weed things out $[\ldots]$ and check what's quite out of date now and what we can afford to move on (Bethany).

These files were referred to as acting as a record and of being kept so that "we have a record of it', but they were not the thing that seemed to be seen, by the new editor in post, as 'the' record; rather this was a central database called Centaur: ${ }^{10}$

Centaur would be the main place where all of the record about a book would be because then it's used by production to keep track of production schedules and things so it's something that is used the whole way through from the point of syndication to the point of publication (Bethany).

We have a system called Centaur [...] you create a record for your new book and then there's a lot of information that you have to fill in (Bethany).

Alternatively, but similarly, the retiring editor spoke of how:

there are two forms of filing, of recordkeeping here and one is what we've talked about, the email files and things and the paper file which are part of an editor's working papers $[\ldots]$ and then there is a database $[\ldots]$ and that is where every project that is going to be published needs to be logged (Linda).

This response refers to the paper file more in the context of 'an editor's working papers' than that of a record, and it also places email files in this category. Email was an important factor, impacting as it did on the editors' methods of communication, which were of vital importance in their relationship with authors. The distinction between the situations before and after email were not completely polarised however, as Bethany reported still dealing with authors who did not have email. Further, although she suggested that phone communication might have been more important before email, Linda, who had experienced the days when letters outnumbered emails, 
acknowledged that whilst there had been more phone calls back then, 'the phone has never been particularly important in humanities publishing.'

Probing the distinction between editor's working papers and Centaur ('the record about a book') a bit further, Centaur was then discussed in these terms:

It's useful as a recording document and it's useful as a sort of moving on document, a statistical document, and for consulting, but [...] it's not something you could have a rounded approach to a project. That's not what it's for (Linda).

On this idea of a more rounded approach, Bethany also stated that although Centaur was a good place to look to find out about a project, it had nonetheless been:

incredibly useful for me having those paper files from [Linda], just in terms of getting not just the bare facts of what a project was, but actually seeing the correspondence and getting a feel for what the author might be like, and how they might react to things from what's already been actually discussed.

This comment was in the context of the fact that although Centaur did have a note field, it was a self-censored environment in which that feel of what an author might be like would most likely be reduced to code such as 'sensitive author situation'.

Much more could be said from the gathered data about recordkeeping in the author-editor relationship, but some key findings are these: firstly, in the context of 'the binary opposition of the personal and corporate archive', one way in which this binary clearly manifested itself was in terms of personal and corporate views. How the individual editor needed to view the work (in more personal terms) differed from how the organisation (as a whole) needed to view it (in more functional ones). These views could perhaps be seen to be embodied in different, personal and corporate 'archives' and whereas those materials bunched under the label editor's working papers provided/embodied one, Centaur provided/embodied the other. 
In the past, these two views had been more integrated into a single recordkeeping system, the paper file, but this mechanism did not work well for everyone; for example those who needed only the more organisational view, as described by Linda as follows:

one of the team leads came around, and I was showing her the paper file, and she was simply horrified, because the paper file is actually quite big. And I said, yes, but the material you need is in here, and she said, no, I'm not looking at that [...] it was not pulled out sufficiently for them to be able to use it in the time they had at their disposal.

Different systems therefore now cater for these different views, but even within that of the editor's working papers, there is further fragmentation and duplication across systems, such that the previously acknowledged recordkeeping system for this view, the paper file, is becoming more and more variable. As Linda put it:

the amount of paper that emails have generated over the last twenty years has risen exponentially and so inevitably the paper filing becomes very spotty and therefore less useful because if it's not comprehensive, it's not comprehensively useful, but if it is comprehensive, it's completely unmanageable.

More and more of the working of the editors is left in their email inboxes and these are not (yet) seen as a part of or integrated into a recordkeeping system. For example, they are not passed on with the role as is the case for the paper files. As Bethany explained: 'I didn't inherit anything from [Linda] digitally [...] I didn't have access to any of her emails, anything like that, so all I had was the paper files'.

This is clearly a loss to Bethany of the personal view that Linda held of the work, but it is also a loss of that view to Linda, who said of the closure of her email inbox following her retirement: 
It's closed to me from the day I walk out of the Press, so I lost 23 years of what was not entirely professional - because I had become very friendly with authors. [...] the Press archive and the Press identity from that point of view was closed.

The challenges that email preservation presents are being examined by researchers, and reports such as the recent The Future of Email Archives by the Council of Library and Information Resources underline the importance of this work:

Email represents an increasingly important part of the historical record. Preserving and ensuring access to this record are therefore central to the functions and values of archives and archivists. Until we can meet the challenges of email archiving, responsible custody is undermined, accountability is abandoned, and, ultimately, the historical record is imperiled. In short, the problem won't take care of itself, and the time to act is now. ${ }^{11}$

In an earlier report for the Digital Preservation Coalition, Christopher Prom discusses the specific issue of email deletion when an employee leaves, emphasising that because the onus is placed upon the end user to take action if they want to save a message, institutions 'pay little cognizance to historical or long-term administrative value of such records. ${ }^{12}$

Apart from the specfic issue of email however, perhaps another way of addressing recordkeeping practice is to think also in terms of mechanisms for re-uniting and building stronger connections between the different views of the organisation and to acknowledge that you can never preserve all the material traces that embody the author-editor relationship. One of those traces, namely the person of the editor, will always be subject to loss.

\section{Findings from a literary scholarship frame}

As Robert Darnton stressed, 'historians have barely begun to tap the papers of publishers, though they are the richest of sources for the history of books, ${ }^{, 13}$ and even though that comment was 
made over thirty years ago, it still holds true. It has, therefore, been enormously useful to collaborate on this research with an archival expert, and to realise, via a more informed understanding of the way archival theory and practice works, what the larger framework that can help manage questions about choice of materials to keep, and how to preserve them, looks like. It is certainly not true, in this case study, that the Press treats their archives as 'garbage', a claim Darnton made about some publishers, ${ }^{14}$ and the efforts that are being made to impose some kind of systematic records protocols are nothing less than heroic, given the scale of the tasks involved: one major UK university Press published over 700 monographs in $2017-2018,{ }^{15}$ so even just taking this one class of book into account, keeping organised, stable, secure records for each of these, including the curated correspondence between editors and authors, would be a task involving a considerable investment. Pursuing this research certainly made it very evident that record-keeping is far from the straightforward, logical set of acts scholars can assume they must be, and that embedded within fast-evolving online workflows, maintaining any kind of robust records system is a major challenge.

For example, the interviews showed very distinctly that publishing staff are, quite understandably, focussed on their core responsibility of getting books out on time, and to a high standard. Beyond what information might be useful in the future in terms of new editions, reprints, or financial questions, correspondence that deals with anything more is seen as superfluous to space (whether physical or digital) and therefore expendable, e.g. 'I don't, I'm not really conscious that I've ever had an email exchange with someone where I've thought, you know, I must keep this for posterity' (Bethany).

The interviews also seemed to support a view that both editors and authors were becoming increasingly pressurised. For example: 
both sides I think are under more stress because I think that the authors' need to publish to fulfil all sorts of external requirements has really accelerated over that period and to some extent skews both the timing and the nature of the work that's coming in and I think from the editor's point of view the bottom line becomes ever more important and bringing through things, you know, fulfilling the budget, $[\ldots]$ and all those things also is much tighter now (Linda).

However, the findings were more mixed with regard to what the impact of this had been on the author-editor relationship. Both editors described similarities in their relationships with authors, both acknowledged that those relationships were felt to be personal ones, to some degree, albeit not necessarily equally on both sides. Linda described an anecdote told to her by her predecessor, who had gone to a social event hosted by a couple of her authors, only to inadvertently overhear them criticising publishers:

They didn't make that connection because for them the publishing end was just a function and there was nothing personal in it, I think they were mortified when they saw that she was there, but she was mortified because she had thought they had a relationship (Linda).

Then again, both editors highlighted the fact that, in their many dealings with many authors, there was no one size fits all pattern for those relationships; different types of project (commissioned or not commissioned) did tend to establish different types of relationship, but even within those types there was always further difference: '[The relationship] varies a lot, and it would vary a lot depending on the project and depending on the author' (Bethany). Indeed, one editor made the following aside, indicating at the end of it a dislike of generalising about the individuals who were her authors:

I have a certain kind of respect for the author who says I am not changing anything - you know and in a way they know, but in another way they don't - I hate calling them they so please excuse that because it's not a they (Linda). 
Given the increasing pressure on all sides, there was a sense perhaps that it was harder to keep track of things. For example, Bethany said of her predecessor, '[she] didn't seem to have any spreadsheets or anything', this leading on from her comment that 'I use spreadsheets a lot to keep track of things and I don't think that any of the older editors do and I've no idea how they keep track of things and it must just be mentally'. In this light, the importance of the editor's relationship with authors as individuals was perhaps explained by the following comment: when I took over [Linda's] list there's probably somewhere between two and three hundred projects that were ongoing in some way that I had to try and get my head round and it's very hard to sort of create a person who you can hang that information off until you've met them. Once you've met someone and you have a face it's much easier to sort of solidify them and their project and all of the potential issues and things there might be around that in your mind (Bethany).

The only evidence for definite change in the author-editor relationship came in the context of discussion about a new series, one that was employing a different workflow, based more on that of journal publishing:

it's a project, a product which was designed to make the most of digital and one of the things is there being speed so the ability to publish something very quickly [ . . ] so whereas normally a book would be entirely dealt with by sort of the editor or the editorial assistant until when it was handed over to production with [this] it goes over to production much sooner (Bethany).

In this case, there was perhaps more of a sense of the editor losing their personal relationship with an author:

I think the idea was that because it should all be fairly automated that [ . . ] you shouldn't really need to do very much, you should just kind of make sure that the right emails go to the right person and that the right buttons are pressed at the right time rather than the usual book review 
process which would be me sitting there and thinking who could review this book and sending them an email and a much more sort of personal process (Linda).

Obviously this was only a very small study, but it does perhaps suggest that there is more to be explored when positing that 'hands-on engagement between editors and authors is less common than it was two decades ago.' ${ }^{16}$ Not least it perhaps suggests that any such exploration would only be enriched if it also took into consideration the way in which such a change might be evidenced in and impact on the creation of the material traces of the workings of that relationship. For, it is here perhaps that any losses will become most materially realised. For, as Bethany puts it 'that kind of streamlining to make the most of the digital product probably does come at the expense of losing some of the sort of archive of the life of it'.

\section{Developing a more common frame of reference}

In the course of this research, it became apparent that a number of past encounters have taken place between recordkeepers and publishing archives. For example, Laura Millar has shown sustained interest in advocating for the value of publishers' archives and for the better management of their records, returning to this subject on a number of occasions. ${ }^{17}$ Similarly, albeit in the slightly different context of music publishing, Helen Samuels is credited for her part in advising a United States of America Music Library Association/Music Publishers Association Joint Task Force on Publishers' Archives that led to some guidelines being produced in the mid1990s. ${ }^{18}$ These treatments tend to rest at a fairly general level, but the odd in-depth investigation of particular issues can also be found, for example in Susan Hamburger's discussion of access to rejected manuscripts held in publishing archives. ${ }^{19}$ In her encounters, Millar has drawn parallels between archivists and authors/writers: 
Authors help people understand themselves and their society. Writers explore ideas, communicate information, present arguments, and express emotions. Archivists also help individuals and societies understand themselves; they acquire, preserve and make available the documentary evidence of the past in original, irreplaceable historical records. ${ }^{20}$

In this study, however, and with the focus on the author-editor relationship, an emerging parallel between recordkeeper and editor can also be drawn and, moreover, drawing this parallel can perhaps shed light on the challenges these two roles share in new and interesting ways.

Listening to the editors speak about their function, a sense of familiarity was felt by the archival researcher. For example, in the way in which a sense of responsibility was felt towards their authors, with the awareness that 'you always know that it's someone's very long-term piece of work that you're dealing with' (Bethany). This role was also discussed in terms of the editor being the person 'who's going to sort of shepherd it through' (Bethany). It was acknowledged that in this role there was some intervention and dialogue:

it will certainly be a case of discussing things with the author but it will not be a question of discussing the argument in chapter three or anything like that. It's more a matter of - this topic, do you really think it needs that kind of treatment, do you really need 450 pages to talk about five years in the life of some author or something like that (Linda).

This response highlighted how there were perhaps limits to how much the editor would be able to engage with the author's argument, but that they did 'need to be able to know enough in order to shape a project' (Linda). In this way, the interviewed editors seemed to be sketching out a role for themselves in tweaking, but not fundamentally shaping, the texts that they were shepherding through to publication. A similarly ambiguous role is mirrored in the ongoing discussion about the recordkeeper as an active agent and not just a passive guardian of material being seen through to long term preservation. 
In undertaking this shaping the editors were influenced by a number of things, e.g. the need to fit within the existing list (of publications in a particular subject area), a sense of prevailing trends in the subject area, and a sense of potential audiences and appeal of the work. These influences also seemed to have parallels in the recordkeeping world, for example in the need to fit within an existing collecting policy, or a sense of the wider research value of the material.

Within this discussion of the editor's role it was also suggested that authors and editors might not share the same view on things:

from the publisher's point of view, the author doing the research and reaching the conclusions is not the whole part of the research project. From the publisher's point of view, it isn't really a successful research project until it has reached the audience it wishes to reach and I think some scholars are more aware of that $[\ldots]$ than others and some scholars I think genuinely don't understand that that is part of the trajectory. They see it as something bolted on the end when they've already finished. (Linda)

As one final illustration of the way in which parallels can be drawn with recordkeepers, it could be argued that in the above perspective, editors have a view that encompasses all four dimensions of the records continuum model (not just create, capture and organise, but also pluralise - the reaching out part of the above quote) in the same way that recordkeepers do. ${ }^{21}$

The records continuum model is of course well known within recordkeeping circles, but working in the context of academic publishing brought this study into contact with the concept of the scholarly record. A recent piece of work by OCLC Research explored the evolving scholarly record in the context of the digital revolution and the fundamental changes this has made to the way in which research is undertaken and published. ${ }^{22}$ This is very much in the context of the digital revolution and the fundamental changes this has brought to the way in which research is 
undertaken and published. The conceptual model that was produced has two parts: one addressing the content of the scholarly record and the other the stakeholder ecosystem associated with the scholarly record. Within the ecosystem, four roles are identified: create, fix, collect and use. There are some parallels with the four dimensions of the recordkeeping continuum model create, capture, organise and pluralise - and it would seem that both editors and recordkeepers share a view that encompasses and seeks to see as a whole all four of these roles or dimensions.

Drawing on this realisation, the research started to lead in a number of directions. Firstly it led to a frame of reference that could encompass both the recordkeeping and the literary scholarship frames, but secondly it also led back to the beginning and to what had perhaps only been implied up until now - a fundamental difference of perspective. For any dialogue between archivists and literary scholars to be successful, differences in perspective, like the one between the author and the editor in the above quotation, must be acknowledged and understood. Shifting to the idea of the scholarly record means shifing to a perspective of the term 'record' that goes beyond a view of it as just an informational resource, a fixed product or version of record: instead it beomes a complex system inhabited by all the different agents involved in the production of academic work. Dialogue between archivists and literary scholars has not always taken place within this particular shared perspective: making this a priority for the future is a key recommendation of this paper.

\section{Conclusion}

Within the common frame of reference being suggested, literary scholars and archivists can start to work together on a wider, more fundamental set of research questions about scholarship: how is the scholarly record created, made discoverable, secure, and conserved. In his 2014 book on 
memory and scholarship, Jerome McGann posed the question: what do scholars want? His answer was that:

Whether we work with digital or paper-based resources, or both, our basic needs are the same.

We want our cultural record to be comprehensive, stable, and accessible. And we want to be able to augment that record with our own contributions. ${ }^{23}$

McGann's focus is on the urgent need to return to more philological research methods to grapple with the challenges thrown up by the re-editing of the archive of cultural works within a network of digital systems, and 'because all of our educational work, intra- as well as extramural, depends upon the clarity and comprehensiveness of the documentary record, these changes in the fundamental character of the record have a correspondingly significant effect on public education. ${ }^{24}$ His work underlines the far-reaching implications of the move to digital for our cultural and intellectual inheritance, as well as educational practice, and he uses arguments based on bibliographical theories to show how vital the histories embedded in texts are as part of these contexts. Using D. F. Mackenzie's 'sociology of texts' as a starting point, McGann suggests a new paradigm, a 'double helix with one strand comprised of a work's production history and the other of its reception history. ${ }^{, 25}$ This matters because, as Kathleen Fitzpatrick has pointed out, the move to more digitally based texts (and therefore more digitally based workflows) has to take into account the wider contexts of academic life: how tenure is obtained, how academics do their work, communicate their work, and how that work is consumed by readers inside and outside of the academy, and 'these changes cannot be simply technological; they must be both social and institutional'.26

Scholarship, and the publication, dissemination and consumption of scholarly texts, takes place in a landscape where McGann's double helix of codes is already being challenged: it is 'starting to unravel as new, genetically modified digital formats force us to rethink what the 
academic book can be.' ${ }^{27}$ The digital revolution is not over, and what is needed, urgently, is more collaboration between all the agencies involved, in order to protect the scholarly record of the future. As Tom Mole stresses:

Most printed books exist relatively well in regimes of benign neglect. . The same is not true of electronic formats, which often become irrecoverable after only a few years due to obsolescent hardware and software. We therefore need to consider who will bear the ongoing responsibility and cost of maintaining long-term access and usability of academic books created in digital formats, and the datasets associated with them. This means remixing the division of labour that currently exists among faculty, publishers, and librarians. ${ }^{28}$

It is noticeable in this quotation that recordkeepers and the recordkeeping activity of those mentioned are curiously absent and one of the main conclusions of this research is that the concept of and debate around the scholarly record, after or even before, the digital revolution, would be enriched by its taking greater account of the difference of perspective between seeing the record, in the case the scholarly record, as a complex system, and seeing the record as a resource to be exploited for the purposes of scholarship. Literary scholars have long relished the possibilities that records offer them, the way in which

From those bushels of notes, representing data tracked down during many an adventurous quest, may come a radically revised interpretation of the life and character of a great poet, or of the meaning of his most important poems. ${ }^{29}$

Literary scholars have also, to return to Helen Gardner's statement on literary scholarship, been concerned to retain the crucial ability to 'confidently [. . . ] check the statements of authorities against the documents on which they are based'. Philological research methods are not the only ones that will aid scholars working within digital systems connected to cultural outputs: to 
augment McGann's argument, they will also, more vitally, rely on engagement with recordkeeping theory and practice, key elements, of the integrity of the system they work within. This paper has led to a common frame of reference, that of the scholarly record, that may prove to be a productive space in which dialogue and collaboration between archivists and literary scholars can more easily take place. Certainly it is one which the two authors wish to explore further together. Other findings, taken as they are from such a small study, will most definitely need additional research to test if they are in any way helpful in suggesting strategies for after the digital revolution. Some evidence for a less hands-on relationship between editors and authors was found, but this was balanced by even more evidence that suggested it was also to some extent unchanged. Then again, evidence was also found for changes to recordkeeping, including for example: greater fragmentation in both good (more efficient operation due to the separation and specialisation of the different views of the work of the organisation required) and bad (proliferation of editor's working view across multiple systems) ways, and a major issue around email, as not yet incorporated into a recordkeeping system that could support knowledge transfer and the ongoing operation/survival of the Press (despite the loss of individuals from it).

This article makes no concrete suggestions in the light of these changes because, when attempts to do so were made, the tendency became to reinforce the same sort of relationship between archivists and literary scholars that this article has sought to move beyond. The terms of engagement between us do not need to just be objects, in a digital or paper form, that we pass between us. Rather those terms can be enhanced and expanded to include the future of the scholarly record more generally and in a more abstracted and complex sense.

We must reach out to and learn how to engage on this level, because what we face in the humanities and in the academy more widely, 'is less a material obsolescence than an institutional 
one; we are entrenched in systems that no longer serve our needs. But because we are, by and large, our institutions - or rather, because they are us - the greatest challenge we face is not that obsolescence, but our response to it. ${ }^{30}$ This view, from the academy, is met and given a way forwards by archival and record-keeping research, which asserts that if a shift in approach is made, as outlined above, from concern about saving the actual record to 'a renewed focus on the context, purpose, intent, interrelationships, functionality, and accountability of the record, its creator, and its creation processes, wherever these occur' then this:

redefined sense of provenance also offers archivists, their sponsors, and their researchers a means to stop drowning in an overwhelming sea of meaningless data and to find instead patterns of contextualized knowledge, which in turn leads to the hope for wisdom and understanding. ${ }^{31}$

\section{Acknowledgements}

We would like to thank the editors at Cambridge University Press who gave us their time and their feedback, without which this research would not have been possible, and to Kevin Taylor, the Director of Syndicate Affairs, for giving his approval for the research to take place.

\footnotetext{
1 Terry Cook, 'Electronic Records, Paper Minds: The Revolution in Information Management and Archives in the Postcustodial and Postmodernist Era', Archives and Manuscripts, vol. 22, no. 2, November 1994, pp. 300-28.

${ }^{2}$ Robert Johnston and Kimberley Marwood, 'Action Heritage: research, communities, social justice', International Journal of Heritage Studies, vol. 23, no. 9, October 2017, pp. 816-831.

${ }^{3}$ Helen Gardner, 'The Academic Study of English Literature,' Critical Quarterly, vol. 1, no. 2, June 1959 , p. 111.

${ }^{4}$ Iain Stevenson, Book Makers: British Publishing in the Twentieth Century, The British Library, London, $2010, \mathrm{p}$. xviii.

${ }^{5}$ Geoffrey Crossick, Monographs and Open Access: A Report to HEFCE, January 2015, available from $<<$ http://webarchive.nationalarchives.gov.uk/20180322111256/http://www.hefce.ac.uk/pubs/rereports/year/2015/mo nographs/>>, accessed 6 November 2018, p. 15.

${ }^{6}$ Michael Jubb, Academic Books and their Futures, June 2017, section 6.3.1, available at $<<$ https://academicbookfuture.files.wordpress.com/2017/06/academic-books-and-their-futures_jubb1.pdf $>>$, accessed 6 November 2018.
} 


\footnotetext{
${ }^{7}$ Sue McKemmish and Michael Piggott, 'Toward the Archival Multiverse: Challenging the Binary Opposition of the Personal and Corporate Archive in Modern Archival Theory and Practice', Archivaria, vol. 76, Fall 2013, p. 115. ${ }^{8}$ See for example; Catherine Hobbs 'The Character of Personal Archives: Reflections on the Value of Records of Individuals' Archivaria, vol. 52, Fall 2001, pp. 126-35; Rob Fisher, 'In Search of a Theory of Private Archives: The Foundational Writings of Jenkinson and Schellenberg Revisited', Archivaria, vol. 67, Spring 2009, pp. 1-24; Jennifer Meehan, 'Rethinking Original Order and Personal Records', Archivaria, vol. 70, Fall 2010, pp. 27-44.

9 'Pending' refers to projects which have yet to go to the Press Sundicate for formal approval.

${ }^{10}$ Centaur is the publisher's in-house bibliographic database. It is used to manage the processes for Elements and books from pre-contract stages through to publication and post-publication stages.

${ }^{11}$ Council on Library and Information Resources, The Future of Email Archives: A Report from the Task Force on Technical Approaches for Email Archives, August 2018, p. 3, available at <<https://clir.wordpress.clir.org/wpcontent/uploads/sites/6/2018/08/CLIR-pub175.pdf >>, accessed 15 January 2019.

${ }^{12}$ Christopher J. Prom, Preserving Email, Digital Preservation Coalition Technology Watch Report 11, Digital Preservation Coalition, n.p., 1 December 2011, p. 16, available at <〈https://doi.org/10.7207/twr11-01〉〉, accessed 15 January 2019.

${ }^{13}$ Robert Darnton, 'What is the History of Books?' Daedalus 111, no. 3, Summer 1982, p. 76 available at $<<$ http://www.jstor.org/stable/20024803〉>.

14 ibid.

${ }^{15}$ Cambridge University Press Annual Report for the year ended 30 April 2018, p. 10, available at $<<$ https://www.cambridge.org/files/5015/3452/7174/Annual-Report-2018.pdf $〉>$, accessed 6 November 2018.

${ }^{16} \mathrm{Jubb}$, section 6.3.1.

${ }^{17}$ See for example Archival Gold: Managing and Preserving Publishers' Records, Canadian Centre for Studies in Publishing Press, Vancouver, Canada, 1989, and a follow up article version, The Story Behind the Book: Preserving Authors' and Publishers' Archives, Canadian Centre for Studies in Publishing Press, Vancouver, Canada, 2009. Also articles such as 'Myths and realities: records and archives management for publishers', Journal of Scholarly Publishing; North York, vol. 28, no. 1, October 1996, pp. 35-54.

${ }^{18}$ Kent Underwood, 'Archival Guidelines for the Music Publishing Industry', Notes, vol. 52, no. 4, June 1996, p. 1112 .

${ }^{19}$ Susan Hamburger, 'Rejected Manuscripts in Publishers' Archives: Legal Rights and Access', Journal of Archival Organization vol. 9, iss. 1, January 2011, pp. 45-58.

${ }^{20}$ Millar, The Story Behind the Book, p. 8.

${ }^{21}$ For more details of the records continuum model, see: Frank Upward, 'Structuring the Records Continumm Part 1: Postcustodial Principles and Properties', Archives and Manuscripts vol. 24, no. 2, November 1996, pp. 268-85; Frank Upward, 'Structuring the Records Continuum Part 2: Structuration Theory and Recordkeeping', Archives and Manuscripts, vol. 25, no. 1, May 1997, pp. 10-35; and Frank Upward, 'Modelling the Continuum as Paradigm Shift in Recordkeeping and Archiving Processes, and Beyond: A Personal Reflection', Records Management Journal, vol. 10, no. 3, 2000, pp. 115-39.

${ }^{22}$ Brian Lavoie, Eric Childress, Ricky Erway, Ixchel Faniel, Constance Malpas, Jennifer Schaffner, and Titia van der Werf, The Evolving Scholarly Record, OCLC Research, Dublin, Ohio, 2014, available at $<<$ https://www.oclc.org/research/publications/library/2014/oclcresearch-evolving-scholarly-record-2014overview.html $>$, accessed 15 January 2019.

${ }^{23}$ Jerome McGann, A New Republic of Letters: Memory and Scholarship in the Age of Digital Reproduction, Harvard University Press, Cambridge, Massachusetts, 2014, pp. 131-32.

24 ibid., p. 20.

25 ibid., p. 82.

${ }^{26}$ Kathleen Fitzpatrick, Planned Obsolescence, New York University Press, New York, 2011, p. 8.

${ }^{27}$ Tom Mole, 'The Academic Book as Socially-Embedded Media Artefact', in The Academic Book of the Future, ed. Rebecca E. Lyons and Samantha J. Rayner, Palgrave, London, 2016, p. 12.

${ }^{28}$ ibid., p. 15.

${ }^{29}$ Richard D. Altick, The Scholar Adventurers, The Free Press, New York, 1950, p. 318.

${ }^{30}$ Fitzpatrick, p. 13.

${ }^{31}$ Terry Cook, 'What is Past is Prologue: A History of Archival Ideas Since 1898, and the Future Paradigm Shift', Archivaria, Spring 1997, issue 43, p. 49.
} 